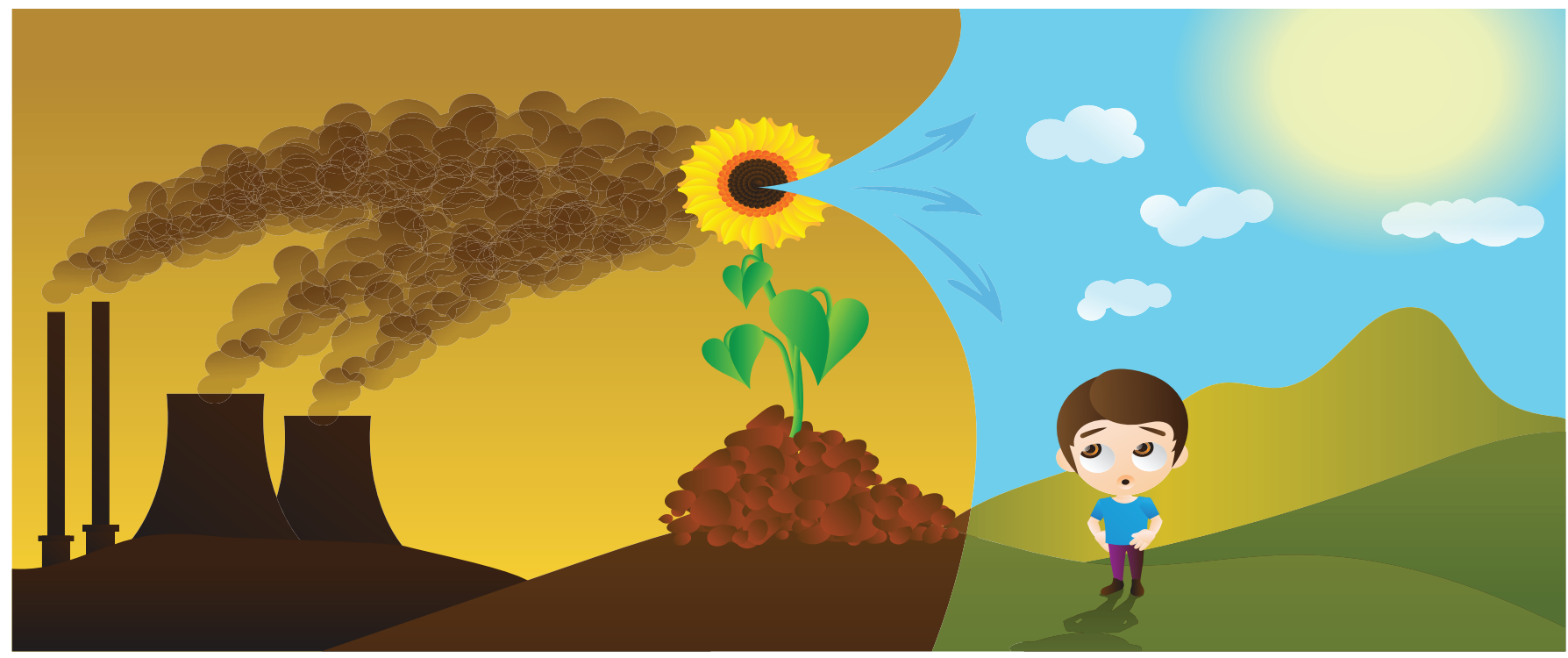

\title{
REMOVING HARMFUL GREENHOUSE GASES FROM THE AIR USING ENERGY FROM PLANTS
}

\section{Daniel L. Sanchez', Daniel M. Kammen ${ }^{1,2}$}

${ }^{1}$ Energy and Resources Group, University of California Berkeley, Berkeley, CA, USA, ${ }^{2}$ Richard and Rhoda Goldman School of Public Policy, University of California Berkeley, Berkeley, CA, USA

\section{REVIEWED BY: \\ INTERNATIONAL SCHOOL OF LAUSANNE}

Carbon dioxide (written as $\mathrm{CO}_{2}$ ) releases from fossil fuels cause climate change, a warming of the earth that causes more intense heat waves, extreme weather, and other negative impacts on our world. How can we stop future climate change? One option is to remove $\mathrm{CO}_{2}$ from the air around us. Here, we describe an original carbon dioxide removal technology called bioenergy with carbon capture and sequestration (BECCS). BECCS produces energy from plants, grasses, or trees while removing $\mathrm{CO}_{2}$ from our atmosphere. Scientists are just beginning to understand the role that BECCS can play in reducing climate change. We describe recent research that shows how the world might build electricity systems - a network that delivers electricity to your home - that remove, rather than release, $\mathrm{CO}_{2}$. These systems are very different from our current electricity systems, which use large amounts of fossil fuels.

We know that the Earth's atmosphere acts like a greenhouse: rays from the sun enter, heating the air and the ground. Instead of leaving the greenhouse as they came in, this heat is trapped by the walls and ceiling, making the greenhouse warmer than the air outside. This is just like a car on a hot day: light passes freely 
CLIMATE CHANGE

a change in average worldwide or regional weather patterns.

CLIMATE CHANGE MITIGATION

actions that reduce the impacts of future climate change.

CARBON DIOXIDE REMOVAL

actions that remove $\mathrm{CO}_{2}$ from the atmosphere, which will reduce future climate change.

INTERGOVERNMENTAL PANEL ON CLIMATE CHANGE

a group of scientists from around the world that assesses information to understand the risks climate change. through the window (more than 90\% gets through), but after being absorbed by the seats and upholstery, this energy is re-released as heat, which the windows reflect back into the interior. Hence, the heat can enter but cannot escape and the car will get warmer. Earth has its own greenhouse - an atmosphere, a blanket of air that traps heat through a process known as the "greenhouse effect." The greenhouse effect is a good thing - without an atmosphere the earth would be about $33^{\circ} \mathrm{C}\left(60^{\circ} \mathrm{F}\right)$ colder and most of the water on the planet would be ice! The gases that heat the earth are known as greenhouse gases, the most well known of which is carbon dioxide (chemically written as $\mathrm{CO}_{2}$ ).

However, too much of $\mathrm{CO}_{2}$ in our air can be a bad thing. Humans are responsible for producing large amounts of $\mathrm{CO}_{2}$. Every day we use fossil fuels (such as coal, oil, or natural gas, which we find deep underground in solid, liquid, or gas forms) in our cars or power plants, or we cut down forests. All these activities combined have caused the amount of $\mathrm{CO}_{2}$ in our atmosphere to increase to levels not seen on earth in 55 million years. This increase in greenhouse gases heats the earth. The increase in temperature causes climate change, which is a change in average worldwide or regional weather patterns. Scientists project that climate change will cause a rise in sea level, more intense heat waves, extreme weather, species extinction, and other negative impacts on our world.

Luckily, there are several steps that we can take to reduce the impacts of future climate change. Scientists generally divide these helpful actions (known as "climate change mitigation") into three categories: reducing $\mathrm{CO}_{2}$ and other harmful greenhouse gas emissions (the release of these gases into the atmosphere), reducing the amount of sunlight that reaches the earth's surface, or removing $\mathrm{CO}_{2}$ from the atmosphere. Each of these actions has different costs, benefits, and risks. It is important for governments and policymakers to understand how large of a part each of these solutions can play in society's response to climate change.

Let us focus on carbon dioxide removal (CDR) from the atmosphere. How much $\mathrm{CO}_{2}$ removal might we need to do in order to fight climate change? One estimate comes from the Intergovernmental Panel on Climate Change (IPCC), a group of scientists from around the world working together to answer these questions. The IPCC report contained a strict plan for limiting temperature increases so that climate change could be slowed. This IPCC plan includes both ways to decrease our $\mathrm{CO}_{2}$ output, as well as ways to remove carbon from the atmosphere using CDR technologies. In fact, this plan requires CDR technologies to remove an amount of $\mathrm{CO}_{2}$ equal to $25 \%$ of the amount produced worldwide, by the year 2100 . The rest of the $\mathrm{CO}_{2}$ reductions would have to come from other actions, including new energy sources that do not produce $\mathrm{CO}_{2}$, such as wind and solar power. Figure 1 shows what $\mathrm{CO}_{2}$ emissions might look in the future if we act to reduce climate change ("climate change mitigation") or if we choose not to reduce emissions ("business as usual"). 


\section{FIGURE}

The world's carbon dioxide emissions for "Business as Usual" and "Climate Change Mitigation" scenarios. The figure shows how $\mathrm{CO}_{2}$ emissions (in $\mathrm{PgC} /$ year, an amount of $\mathrm{CO}_{2}$ emitted every year) evolve in the future. In the

"Business as Usual" scenario, we assume that the world continues to use fossil fuels the same way as we have done in the past, whereas in a "Climate Change Mitigation" scenario, we assume that governments take actions to reduce $\mathrm{CO}_{2}$ emissions. Adapted from IPCC [1].

\section{BIOENERGY WITH} CARBON CAPTURE AND SEQUESTRATION

a technology that removes $\mathrm{CO}_{2}$ from the atmosphere while producing energy products like electricity or fuels.

\section{BIOENERGY}

the production of energy from biomass. This energy is derived from living things, such as plants, grasses, or trees, and can be carbonneutral energy.

\section{CARBON-NEUTRAL} ENERGY

energy that does not produce any $\mathrm{CO}_{2}$ emissions during its production or consumption.

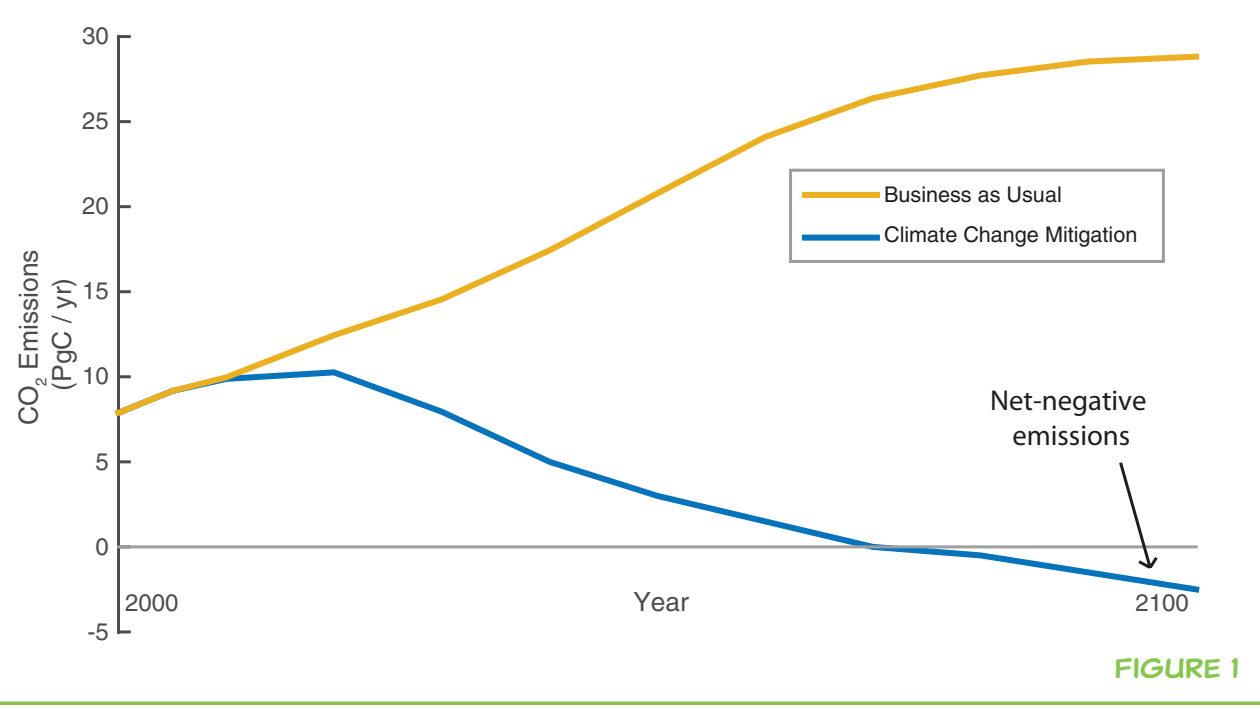

There are several ways to perform CDR. Each of these ways has different costs and would remove a different amount of $\mathrm{CO}_{2}$ from the atmosphere. One idea is called direct air capture of $\mathrm{CO}_{2}$, an expensive procedure that "scrubs," or removes, carbon dioxide directly from the air we breathe. Other ways of removing $\mathrm{CO}_{2}$ from the atmosphere include storing more carbon in trees, soils, or the ocean. One new technology for removing $\mathrm{CO}_{2}$ is known as bioenergy with carbon capture and sequestration (BECCS). BECCS removes $\mathrm{CO}_{2}$ from the atmosphere while producing valuable energy products, such as electricity or fuels. What is more, BECCS can also replace dirtier forms of energy production from fossil fuels. Because of these characteristics, scientists believe that BECCS could play a large role in reducing future climate change.

How does BECCS work, and why does it remove carbon dioxide from the atmosphere? Let us look at how this new technology removes harmful greenhouse gases from the air using energy from plants.

Humans have been producing energy from biomass - material derived from living things, such as plants, grasses, or trees - for their entire existence. We call this energy from biomass bioenergy. For example, early humans produced heat from plants using fire, just like you do when you build a campfire. Today, we use biomass to produce heat, electricity, or transportation fuels around the world. Biomass can be a carbon-neutral energy source, which means that it does not increase the amount of $\mathrm{CO}_{2}$ in the atmosphere. This is because the $\mathrm{CO}_{2}$ released when producing energy is the same as the $\mathrm{CO}_{2}$ taken from the air to grow the biomass (Figure $2 \mathrm{~A}$ ). This $\mathrm{CO}_{2}$ is taken from the air during plant growth. However, biomass is only carbon-neutral if grown sustainably - that is, if the biomass regrows after it is harvested and does not cause emissions from land (such as cutting down forests). Like wind and solar energy, bioenergy can be an important way to reduce the amount of $\mathrm{CO}_{2}$ created when we produce energy. 


\section{FIGURE 2}

Diagram of $\mathbf{A}$. a bioenergy power plant, and $\mathbf{B}$. a bioenergy with carbon capture and sequestration (BECCS) power plant. Plants remove $\mathrm{CO}_{2}$ from the atmosphere while growing. If we harvest the biomass and burn it in a power plant we can generate electricity. With BECCS, we do not release all the $\mathrm{CO}_{2}$ into the atmosphere, but we separate the $\mathrm{CO}_{2}$ (capture) and store it underground (sequestration).

\section{CARBON CAPTURE} AND

\section{SEQUESTRATION}

\section{a carbon dioxide} management technique that captures $\mathrm{CO}_{2}$ from a source, transports it to a storage site, and stores it underground (sequesters it). Sequestering $\mathrm{CO}_{2}$ underground prevents it from entering earth's atmosphere.

\section{ELECTRICITY \\ SYSTEM}

a network that supplies, transmits, and uses electricity.
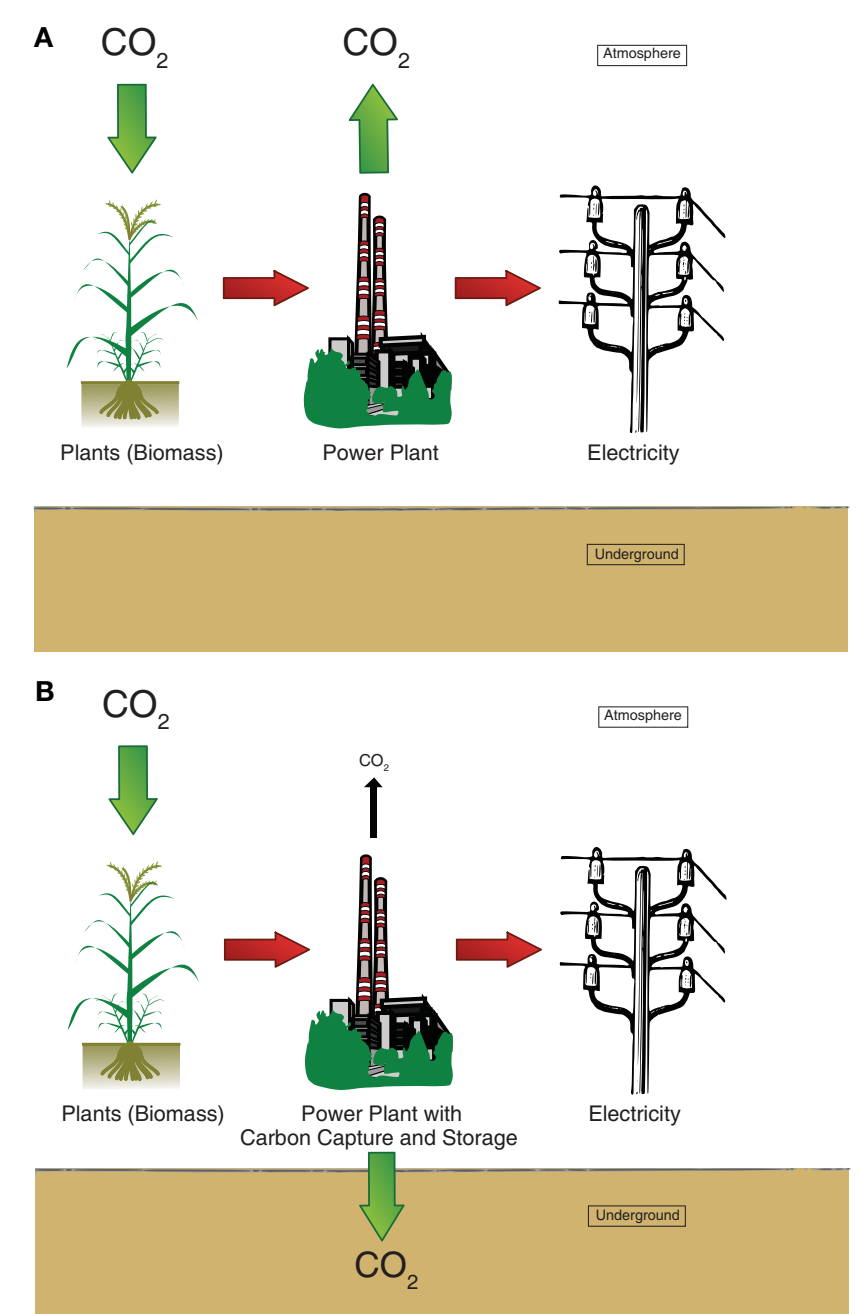

FIGURE 2

Carbon capture and sequestration (CCS) is a $\mathrm{CO}_{2}$ management technique that captures $\mathrm{CO}_{2}$ from a source (such as a power plant), transports it to a storage site, and stores (sequesters) it underground [2]. As a result, $\mathrm{CO}_{2}$ emissions that would normally enter the atmosphere are instead sequestered underground for centuries or longer. By preventing $\mathrm{CO}_{2}$ from entering the atmosphere, CCS reduces future climate change. Most scientists imagine using CCS in existing or future power plants that burn fossil fuels (such as coal, oil, and natural gas), to reduce $\mathrm{CO}_{2}$ emissions from these plants by as much as $90 \%$. Although scientists and engineers have built the technology necessary for CCS, there are still not many power plants using this technology. In the future, we will need CCS in our electricity system, which makes electricity and delivers it to our homes. The electricity system is responsible for a large amount of the world's $\mathrm{CO}_{2}$ emissions.

Bioenergy with carbon capture and sequestration uses both bioenergy and CCS to produce energy and remove $\mathrm{CO}_{2}$ from the atmosphere (Figure 2B). Instead of releasing $\mathrm{CO}_{2}$ during energy production, as traditional bioenergy 
technologies do, $\mathrm{CO}_{2}$ is instead captured and stored using CCS technologies. The result is electricity or fuels that remove, rather than release, $\mathrm{CO}_{2}$. BECCS is different from other CDR technologies in that it produces energy, instead of only removing $\mathrm{CO}_{2}$ from the air. As a result, it could also replace power plants operating on fossil fuels, such as coal, oil, or natural gas.

Energy and climate scientists, like those at the IPCC, are just beginning to understand the role that BECCS can play in reducing climate change. Computer models used by the IPCC predict that BECCS and other CDR technologies will be very useful, but they are still missing several very important details [1]. For example, we would like to know how much biomass is available for energy production, and where it is located. This is important because it tells us how much energy we might be able to create. We also need to understand where we might store carbon dioxide underground. These locations for underground sequestration might not be in the same place as the biomass we need! Finally, we must understand the systems where BECCS might be used, like the electricity system that delivers electricity to our homes. Understanding and making sense of all of this information is a job for engineers, geologists, and other scientists across the world.

To get a better understanding of how BECCS might be used, we used computer models to explore using BECCS in the electricity system of Western North America, which includes parts of the United States, Canada, and Mexico [3]. This model collects important information about where biomass is located and possible locations for underground sequestration. The model also contains important details about how engineers can plan the electricity system in the future. All of the information in the model requires large supercomputers, which are computers with a very high level of computational capacity. These supercomputers can be 50 million times faster than your laptop! Using supercomputers can help us to understand BECCS better than we can use IPCC models.

The first step in understanding how BECCS might be used is to understand how much biomass is available, and where it is located. Biomass contains less energy than the same amount of fossil fuels, and is more spread out around the earth than the concentrated fuels from coal mines, or oil and gas fields. Western North America contains biomass from forests, agriculture, and the wastes we produce, like wood from when we build or tear down buildings. This supply of biomass is limited by its ability to grow back after being used, the steps we take to ensure that we do not degrade our land, water, or air, and the amount of available land to grow plants. Other scientists interested in energy from biomass have built models to estimate biomass availability. We use these existing estimates to create a biomass "supply curve" (Figure 3 ). This supply curve shows the price and quantity of available biomass. The amount of biomass available for energy production using BECCS could fill about 10\% of the electricity demand of Western North America in 2050. 
FIGURE 3

A supply curve for biomass. This figure shows the quantity of biomass available, and its cost. We classify biomass as wastes (what we throw away), residues (wastes left on our farms or in our forests), or dedicated feedstocks (plants that we grow explicitly for bioenergy). Adapted from Sanchez et al. [3].

\section{FIGURE 4}
A. Electricity produced (average generation in GW, an amount of energy over 1 year), and B. $\mathrm{CO}_{2}$ emissions $\left(\mathrm{MtCO}_{2}\right.$ /year, an amount of $\mathrm{CO}_{2}$ emitted every year) in 2050 for an electricity system in Western North America with negative emissions. BECCS allows this system to achieve negative emissions.

Using the data that we can get from our models, we explore the possibility of using BECCS to reduce climate change caused by the electricity system. At the same time, we look at other technologies, such as coal with CCS, and renewable energy technologies (meaning sources that do not "run out," such as wind and solar). We find that BECCS, combined with a large amount of renewable energy from wind and solar power, and far less fossil fuel $\mathrm{CO}_{2}$ emissions, could create an electricity system in Western North America by 2050 that takes more carbon dioxide out of the air than it puts in. These carbon dioxide removing power systems of the future would rely on renewable resources, including biomass, for as much as $88 \%$ of the electricity produced in 2050 (Figure 4). The largest amount of electricity generation would come from wind energy. The remaining electricity would be provided by fossil fuel power plants, especially those using natural gas and CCS.

What is more, since BECCS removes $\mathrm{CO}_{2}$ from the atmosphere, it might allow some $\mathrm{CO}_{2}$ emissions from fossil fuels to continue in the future. Since reducing emissions from our cars or factories can be expensive, BECCS may reduce the cost of slowing climate change. However, the amount of CDR is limited by how much biomass is available.



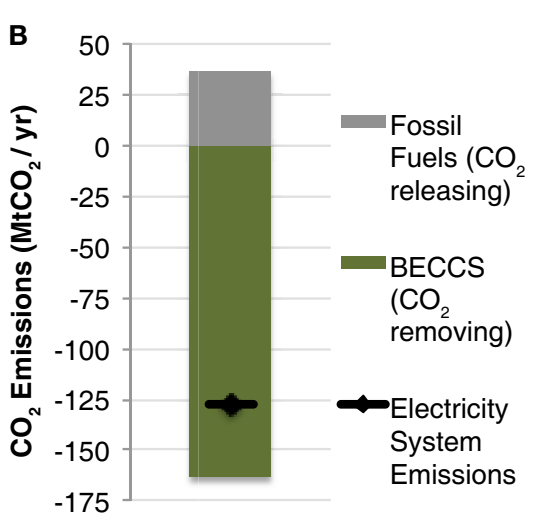

FIGURE 4 
Despite the promise of BECCS, there are still several risks and uncertainties that scientists need to understand in the future. One key issue is the sustainability of biomass needed for BECCS. Efforts to grow more plants or increase biomass availability can impact our environment in negative ways. Planting more plants can increase demand for water, land, and fertilizer. For example, getting enough plants to meet our supply estimate could require a piece of land the size of the state of West Virginia! Another risk is that underground storage of $\mathrm{CO}_{2}$ may not last forever. Carbon dioxide sequestered from CCS could leak into the atmosphere, causing climate change.

The biggest uncertainty with BECCS, however, is that we have little experience building and operating these systems. Who will want to build these facilities? How large will we want to build them? How do we make sure that they make money? How much will they cost? And how can governments support this technology? In the future, we will need to make sure that BECCS technology works efficiently, does not cost too much, and is easy to build and use. By doing this, tomorrow's scientists and engineers can make this technology a reality.

\section{REFERENCES}

1. IPCC. 2014. IPCC WGIll Fifth Assessment Report - Mitigation of Climate Change 2014. Available at: http://mitigation2014.org/

2. Smit, B., Reimer, J. R., Oldenburg, C. M., and Bourg, I. C. 2014. Introduction to Carbon Capture and Sequestration. World Scientific. Available at: http://www. worldscientific.com/sda/1043/intro-carbon-capture-sequestration.pdf

3. Sanchez, D. L., Nelson, J. H., Johnston, J., Mileva, A., and Kammen, D. M. 2015. Biomass enables the transition to a carbon-negative power system across western North America. Nat. Clim. Chang. 5:230-234. doi: 10.1038/nclimate2488

SUBMITTED: 27 April 2015; ACCEPTED: 15 July 2015; PUBLISHED ONLINE: 24 September 2015.

CITATION: Sanchez DL and Kammen DM (2015) Removing harmful greenhouse gases from the air using energy from plants. Front. Young Minds 3:14. doi:10.3389/frym.2015.00014

COPYRIGHT (C) 2015 Sanchez and Kammen. This is an open-access article distributed under the terms of the Creative Commons Attribution License (CC BY). The use, distribution or reproduction in other forums is permitted, provided the original author(s) or licensor are credited and that the original publication in this journal is cited, in accordance with accepted academic practice. No use, distribution or reproduction is permitted which does not comply with these terms. 


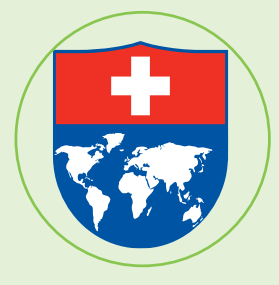

\section{REVIEWED BY}

\section{INTERNATIONAL SCHOOL OF LAUSANNE}

Founded in 1962, the International School of Lausanne is a non-profit, English-language IB World School situated in the heart of the Lac Léman region of Switzerland. We welcome students from 3 to 18 years of age and offer a range of programs and activities designed to develop the unique potential of our students. We celebrate excellence in all its forms, with a well-balanced variety of athletic, creative, and academic opportunities.

\section{AUTHORS}

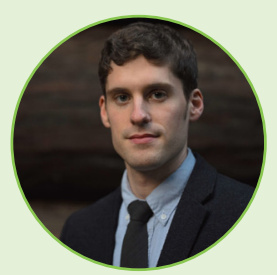

\section{DANIEL L. SANCHEZ}

I use science and economics to help others produce and use energy more cleanly and efficiently. In college, I studied chemical engineering, where I became interested in climate change and renewable energy. Now, I work to help governments make better choices about energy. In my free time, I enjoy hiking, playing music, and seeing friends.



\section{DANIEL M. KAMMEN}

Daniel M. Kammen grew up in Ithaca, New York, and studied to be an astronaut by learning science, getting his pilot license, and watching lots and lots of Star Trek and other science fiction shows. After failing the NASA vision test, he became a professor in the Energy and Resources Group and in the Goldman School of Public Policy at the University of California, Berkeley, where he founded and directs the Renewable and Appropriate Energy Laboratory (rael.berkeley.edu). He and his students believe Bilbo from the Lord of the Rings and are always "ready for another adventure," and work on clean energy and energy access for the poor in projects that range from smart solar and energy efficiency systems for homes, cities, and regions in the United States, to using renewable energy as a tool to provide services and to address conflicts in projects ranging from rural Nicaragua, to Borneo, to community empowerment efforts in Kenya and in South Sudan. Kammen has been a coordinating lead author and supporter of the Intergovernmental Panel on Climate Change, which shared the 2007 Nobel Peace prize, since 1999. Kammen has also served the World Bank as the Chief Technical Specialist for Renewable Energy and Energy Efficiency, and today serves the U. S. Secretary of State as the Energy and Climate Partnership (ECPA) Fellow in energy. Dan lives with his wife, Bamidele, and two teenage daughters, and their awesome dog, Onyx. You can follow Dan and his research program @dan_kammen 